\title{
HER2 gene copy number status may influence clinical efficacy to anti-EGFR monoclonal antibodies in metastatic colorectal cancer patients
}

\author{
V Martin ${ }^{1}$, L Landi ${ }^{2}$, F Molinari ${ }^{1}$, G Fountzilas ${ }^{3}$, R Geva $^{4,5}$, A Riva ${ }^{1}$, P Saletti ${ }^{6}$, S De Dosso ${ }^{6}$, A Spitale ${ }^{7}$, \\ S Tejpar ${ }^{4}$, K T Kalogeras ${ }^{3}$, L Mazzucchelli ${ }^{1}$, M Frattini ${ }^{*}, 1,8$ and F Cappuzzo ${ }^{2,8}$ \\ ${ }^{1}$ Institute of Pathology, Locarno 6600, Switzerland; ${ }^{2}$ Department of Medical Oncology, Istituto Toscano Tumori, \\ Ospedale Civile, Livorno 57125, Italy; ${ }^{3}$ Hellenic Cooperative Oncology Group (HeCOG) and Aristotle University of Thessaloniki \\ School of Medicine, Thessaloniki 54624, Greece; ${ }^{4}$ Department of Digestive Oncology, University Hospital Gasthuisberg, \\ Leuven 3000, Belgium; ${ }^{5}$ Tel-Aviv Sourasky Medical Center, Tel-Aviv 47100, Israel; ${ }^{6}$ Oncology Institute of Southern Switzerland, \\ Bellinzona 6500, Switzerland and ${ }^{7}$ Ticino Cancer Registry, Institute of Pathology, Locarno 6600, Switzerland
}

Background: In metastatic colorectal cancer (mCRC), KRAS is the only validated biomarker used to select patients for administration of epidermal growth factor receptor (EGFR)-targeted therapies. To identify additional predictive markers, we investigated the importance of HER2, the primary EGFR dimerisation partner, in this particular disease.

Methods: We evaluated the HER2 gene status by fluorescence in situ hybridisation (FISH) in 170 KRAS wild-type mCRC patients treated with cetuximab or panitumumab.

Results: Depending on HER2 gene copy number status, patients showed three distinct cytogenetic profiles: 4\% of patients had HER2 gene amplification (R:HER2/CEP17 $\geqslant 2$ ) in all neoplastic cells (HER2-all-A), 61\% of patients had HER2 gain due to polysomy or to gene amplification in minor clones (HER2-FISH + *), and $35 \%$ of patients had no or slight HER2 gain (HER2-FISH - ). These subgroups were significantly correlated with different clinical behaviours, in terms of response rate (RR; $P=0.0006)$, progression-free survival (PFS; $P<0.0001)$ and overall survival (OS; $P<0.0001)$. Patients with HER2-all-A profile experienced the worst outcome, patients with HER2-FISH - profile showed an intermediate behaviour and patients with HER2-FISH + * profile were related to the highest survival probability (median PFS in months: 2.5 vs 3.9 vs 7.6, respectively; median OS in months: 4.2 vs 9.7 vs 13, respectively).

Conclusion: HER2 gene copy number status may influence the clinical response to anti-EGFR-targeted therapy in mCRC patients.

In the era of targeted therapies, monoclonal antibodies (MoAbs) directed against the epidermal growth factor receptor (EGFR/ ErbB-1) have expanded the treatment options for metastatic colorectal cancer (mCRC) patients (García-Foncillas and DíazRubio, 2010). Both cetuximab and panitumumab are active as single agents in chemorefractory metastatic disease as well as in combination with various chemotherapy regimens, but efficacy is restricted to patients with wild-type (wt) KRAS status (Chu, 2012).

The HER (ErbB) family consists of EGFR, HER2 (ErbB-2), HER3 (ErbB-3) and HER4 (ErbB-4) and is responsible for cell proliferation and survival via the activation of the RAS/RAF/ERK and PI3K/PTEN/AKT pathways (Wells, 1999). Several studies have

*Correspondence: Dr M Frattini; E-mail: milo.frattini@ti.ch

${ }^{8}$ Co-senior authors.

Received 24 October 2012; revised 11 December 2012; accepted 12 December 2012; published online 24 January 2013

(c) 2013 Cancer Research UK. All rights reserved 0007-0920/13 
demonstrated that an increased EGFR gene copy number is related to the response to anti-EGFR agents, whereas the deregulation of downstream targets of the EGFR pathway (i.e., mutations in the KRAS, NRAS, BRAF or PIK3CA genes or loss of PTEN protein expression) accounts for the resistance to anti-EGFR MoAbs (Moroni et al, 2005; Frattini et al, 2007; Sartore-Bianchi et al, 2007; Cappuzzo et al, 2008; Scartozzi et al, 2009; De Roock et al, 2010; Van Cutsem et al, 2011). Despite this evidence, only KRAS testing is performed clinically to drive decisions about the use of antiEGFR-targeted agents (www.ema.europa.eu; www.fda.gov). The presence of mutations in the KRAS gene designates the $30-40 \%$ of mCRC patients who are resistant to MoAbs. The characterisation of alterations occurring in additional candidate genes (NRAS, $B R A F, P I K 3 C A$, PTEN) may increase the negative predictive value up to $70 \%$, but it is not sufficient to identify all resistant cases (De Roock et al, 2010; Blanke et al, 2011; Van Cutsem et al, 2011; www.ema.europa.eu; www.fda.gov).

In addition to homodimerization, EGFR can heterodimerize with the other members of the HER family, which, if altered, may influence the response to anti-EGFR agents. A few works have investigated the role of HER2, the primary EGFR dimerisation partner, in this process. In $\mathrm{mCRC}$, two recent studies demonstrated that HER2 gene amplification allows for the activation of downstream signalling even when cetuximab is bound to EGFR, thus leading to drug resistance (Bertotti et al, 2011; Yonesaka et al, 2011). Additionally, in lung cancer, increased HER2 gene copy number may affect the sensitivity to the EGFR inhibitors gefitinib or erlotinib (Cappuzzo et al, 2005; Cappuzzo et al, 2007; Daniele et al, 2007; Hirsch et al, 2009).

On the basis of these data, we investigated whether HER2 gene copy number status may influence the response to cetuximab or panitumumab therapy in a large cohort of mCRC patients.

\section{PATIENTS AND METHODS}

Study population. In an international consortium effort, we retrospectively analysed archival material and clinical data from a series of 396 adenocarcinomas from mCRC patients treated with cetuximab or panitumumab between 2004 and 2010. Cetuximab or panitumumab were administered as single agents or in combination with chemotherapy (in the last case in irinotecan-resistant patients).

Forty-eight cases were recruited at the Institute of Pathology of Locarno (Switzerland), 53 at the Civic Hospital of Livorno (Italy), 101 at the University Hospital Gasthuisberg of Leuven (Belgium) and 194 at the Hellenic Cooperative Oncology Group (HeCOG) and the Aristotle University School of Medicine of Thessaloniki (Greece). Some of the data on partial cohorts have been previously published for other purposes (Frattini et al, 2007; Personeni et al, 2008; De Roock et al, 2010). All patients were characterised for KRAS status. The analysis of the KRAS sequence (codon 12, 13 and 61 in exons 2-3) was performed locally according to the standard protocols for DNA extraction, amplification and sequencing (Frattini et al, 2007; De Roock et al, 2010).

Only patients with wt KRAS status and HER2 gene status evaluation were selected for this study. The investigated cohort was made up of 170 patients. Response rate (RR), progression-free survival (PFS) and overall survival (OS) were available for 158 patients, 162 patients and 153 patients, respectively.

This study was undertaken after approval by the Internal Ethics Review Boards.

Clinical evaluation and tumour response criteria. WHO criteria (only in HeCOG series) or Response Evaluation Criteria In Solid Tumours (RECIST) were used to assess the tumour response. Responders were considered to be those patients who achieved a complete or partial response; non-responders were those with stable or progressive disease. PFS was calculated from the start of cetuximab or panitumumab administration until progressive disease or death, whereas OS was defined as the time from the start of cetuximab or panitumumab treatment until the last followup or death.

HER2 FISH analysis. HER2 testing was performed by fluorescent in situ hybridisation (FISH) at the Institute of Pathology of Locarno (Switzerland) using the LSI HER2-neu/CEP17 probe (PathVysion, Abbott, Baar, Switzerland) on 3-4 $\mu \mathrm{m}$ thick formalinfixed paraffin-embedded tissue sections, as previously described and according to the manufacturer's instructions (Frattini et al, 2007; Martin et al, 2012). FISH handling and interpretation were performed following the European Cytogeneticists Association (ECA) recommendations for FISH on histological sections of solid tumours (http://www.e-c-a.eu/). The signals' evaluation was performed independently by two trained readers (VM and FM) with superimposable results in nearly all the cases (98\% concordance). When non-concordance occurred, additional cells were scored until an agreement was reached. A minimum of 100 morphologically clear, non-overlapping nuclei from at least $8-10$ different areas were scored. Only experiments with at least $90 \%$ hybridisation efficiency were considered.

HER2 gene amplification was defined as the presence of a ratio $(\mathrm{R}) \geqslant 2$ between the HER2 and the CEP17 signals, according to the currently accepted criteria (Sauter et al, 2009). Cases were classified as HER2 amplified (HER2-A) if the percentage of cells with HER2 gene amplification was $\geqslant 10 \%$ (Figure 1A) (Cappuzzo et al, 2005). Among HER2-A patients, those with HER2 gene amplification in the entire tissue section ( $\geqslant 90 \%$ of the cells) were identified and placed in the 'all-A' group (HER2-all-A) (Figure 1B). HER2 gene copy number gain (HER2-CNG) by polysomy was defined as the presence of $\geqslant 4$ copies of the HER2 gene in $\geqslant 40 \%$ of the cells (Figure 1C) (Cappuzzo et al, 2005). Patients with HER2-CNG and patients with HER2-A were grouped as HER2-FISH positive $(H E R 2-F I S H+)$. Those with no or low HER2 gain $(\geqslant 4$ copies of HER2 gene in $<40 \%$ of the cells) and without HER2-A were designated as FISH negative (HER2-FISH - ) (Figure 1D) (Cappuzzo et al, 2005).

EGFR FISH analysis. In a subgroup of 39 patients, for which tissue sections were available, EGFR gene status was assessed by FISH with the LSI EGFR/CEP7 probe according to the manufacturer's instructions (Abbott). EGFR gene amplification was defined as the presence of a $\mathrm{R} \geqslant 2$ between the EGFR signals and the CEP7 signals. Cases were considerd as amplified if $\geqslant 10 \%$ of the cells showed EGFR gene amplification (EGFR-A). Patients were classified according to the EGFR gene copy number as EGFR-FISH + (i.e., $\geqslant 4$ copies of the EGFR gene in $\geqslant 40 \%$ of the cells or EGFR gene amplification in $\geqslant 10 \%$ of the cells) or as EGFR-FISH - (i.e., $\geqslant 4$ copies of the EGFR gene in $<40 \%$ of the cells) (Martin et al, 2009; Varella-Garcia et al, 2009; Sartore-Bianchi et al, 2012).

Statistical analyses. The primary endpoint of the study was to evaluate the impact of the HER2 gene copy number status on the response to anti-EGFR MoAbs in terms of RR, PFS and OS. Chisquare test was conducted to assess the association between HER2 gene status and the response to anti-EGFR MoAbs. The Fisher's exact test was used when expected counts were $<5$. The PFS and OS analyses were performed by HER 2 gene status according to the Kaplan-Meier method, and survival curves were compared using the log-rank test. In order to assess the magnitude of the effect of HER2 gene status profile on PFS and OS, we performed the analysis of the Cox proportional-hazards regression model to estimate the hazard ratio (HR) with the corresponding 95\% confidence intervals (95\% CIs). The level of significance was set at $P<0.05$. The data were analysed using the SAS System V9.1 (SAS Institute Inc, Cary, NC, USA). 

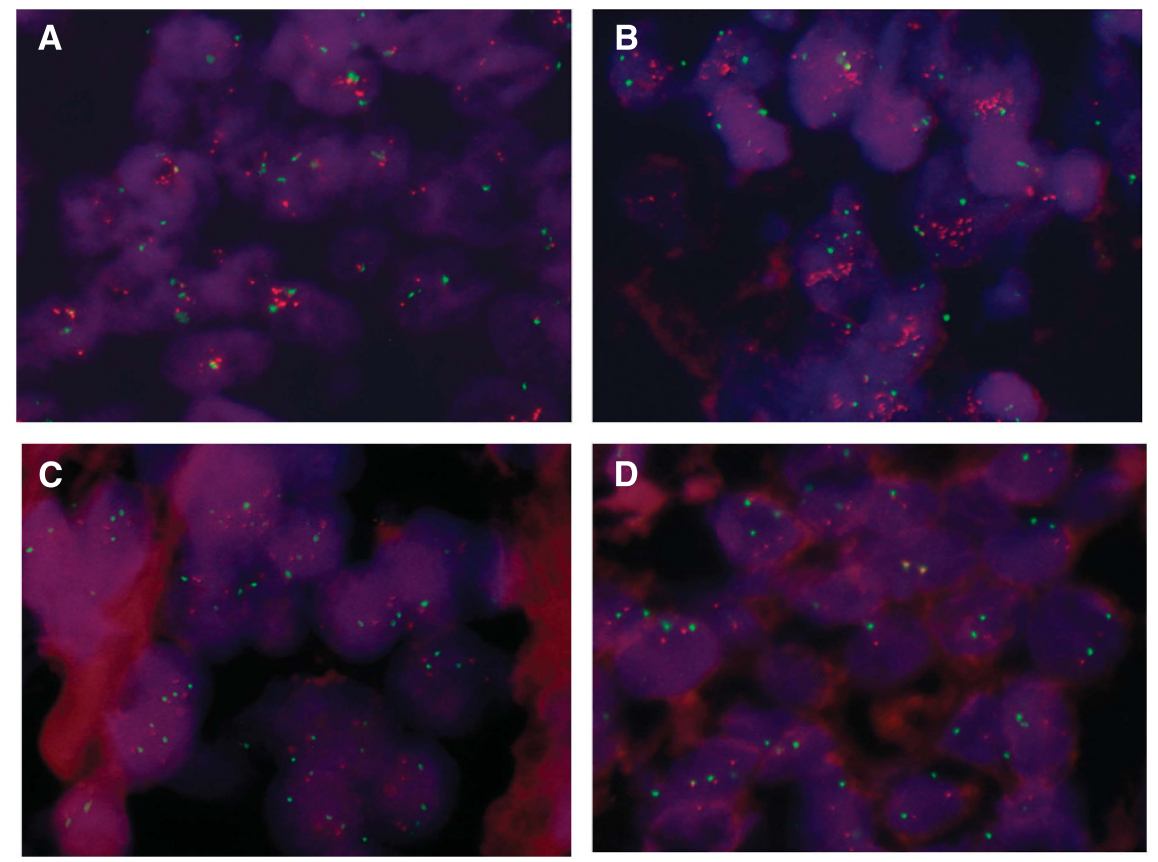

Figure 1. HER2/CEP17 FISH assay (red signal: HER2 gene; green signal (CEP17): centromere of chromosome 17). (A) Tumour showing HER2 gene amplification in a small population (30\%) of the cells (classified as HER2-A case, minor-A profile); (B) tumour showing HER2 gene amplification in all the cells (classified as HER2-A case, all-A profile); (C) tumor showing $\geqslant 4$ copies of HER2 gene in $>40 \%$ of the cells (CNG; classified as HER2$\mathrm{FISH}+$ ); and (D) tumour showing 2 balanced copies of HER2 and CEP17 in > 70\% of the cells (classified as HER2-FISH -).

\section{RESULTS}

Patients. The majority of the patients were male (102 out of 170 , $60 \%$ ), and the median age was 62 years (range 28-76 years; Table 1). Cetuximab or panitumumab was given as a single agent in 12 patients $(7 \%)$. In all the other cases $(N=158,93 \%)$, who experienced resistance to a previous irinotecan-based treatment, the anti-EGFR MoAb was given in combination with chemotherapy (Table 1). Twenty-three patients (13\%) received anti-EGFR drugs as first-line treatment; 83 patients (49\%) as second line, 49 patients (29\%) as third line and $15(9 \%)$ as fourth line or more.

In the entire cohort, the RR was 35\% (complete response in $2 \%$ and partial response in $33 \%$ of the patients), the median PFS was 6.0 months and the median OS was 11.3 months.

HER2 FISH analysis. Out of the 170 eligible patients, 34 (20\%) were classified as HER2-A (median $\mathrm{R}=4.6)$ and $136(80 \%)$ as nonamplified (HER2-non-A; Figure 2). Among the HER2-A patients, 7 patients (4\% of the entire cohort) had amplification in $\geqslant 90 \%$ of the tumour cells (HER2-all-A). The remaining HER2-A patients $(N=27)$ showed amplification in minor clones, with a frequency of cells ranging from 10-60\% (HER2-minor-A) (Figure 2). In the HER2-non-A group, 77 patients showed HER2-CNG due to polysomy (77 out of $170,45 \%)$. Thus, 111 patients (65\%) were classified as HER2-FISH + , accounting HER2-A and HER2-CNG (Figure 2). The remaining 59 (35\%) patients of the HER2-non-A group showed no polysomy and no gene amplification and were classified as HER2-FISH - (Figure 2).

By separating cases with the HER2-all-A profile from the group of HER2-FISH + cases, 104 patients (61\%) exhibited an increased number of HER2 signals due to either HER2 gene amplification in minor clones or to HER2-CNG. This last group was labelled 'HER2-FISH + *' (Figure 2).

Correlation between HER2 gene copy number and response to anti-EGFR MoAbs. All statistical correlations are detailed in Tables 2 and 3.
Table 1. Patients' characteristics, treatment and response to anti-EGFR agents

\begin{tabular}{|c|c|c|}
\hline \multicolumn{3}{|l|}{ Patients $(\mathbf{N}=170)$} \\
\hline \multicolumn{3}{|l|}{ Age (years) } \\
\hline $\begin{array}{l}\text { Mean } \pm \text { s.d. } \\
\text { Median } \\
\text { Range }\end{array}$ & $\begin{array}{c}60 \pm 11 \\
62 \\
28-76\end{array}$ & \\
\hline & Number of cases & Percentage (\%) \\
\hline \multicolumn{3}{|l|}{ Sex } \\
\hline $\begin{array}{l}\text { Male } \\
\text { Female }\end{array}$ & $\begin{array}{r}102 \\
68\end{array}$ & $\begin{array}{l}60 \\
40\end{array}$ \\
\hline \multicolumn{3}{|l|}{ Regimens } \\
\hline $\begin{array}{l}\text { Cetuximab or panitumumab } \\
\text { Cetuximab }+ \text { chemotherapy }\end{array}$ & $\begin{array}{r}12 \\
158\end{array}$ & $\begin{array}{r}7 \\
93\end{array}$ \\
\hline \multicolumn{3}{|l|}{ Response $(N=158)$} \\
\hline $\begin{array}{l}\text { Complete response } \\
\text { Partial response } \\
\text { Non-responders }\end{array}$ & $\begin{array}{r}3 \\
53 \\
102\end{array}$ & $\begin{array}{r}2 \\
33 \\
65\end{array}$ \\
\hline
\end{tabular}

The analyses of patients' outcome according to HER2 gene status revealed that patients with HER2-all-A had significantly worse PFS $(P=0.0012$, Figure $3 \mathrm{~A})$ and $\mathrm{OS}(P<0.0001$, Figure $3 \mathrm{~B})$ than those of the other patients (HER2-non-A and HER2-minor-A patients). In fact, the median PFS was 2.5 months for HER2-all-A patients and 6.7 months for the other patients, with an HR of 3.65 (95\% CI: $1.57-8.46, P=0.0026$; Table 2). The median OS was 4.2 months for HER2-all-A patients and 13 months for the other 


\begin{tabular}{|c|c|c|}
\hline \multicolumn{1}{|c|}{170 wt KRAS mCRC patients } \\
\hline HER2-non-A $=136$ \\
\hline HER2-FISH-=59 \\
\hline
\end{tabular}

Figure 2. Patients' distribution depending on HER2 gene status as detected by FISH. The detailed analysis of HER2 gene copy number allows to recognise different groups of tumours with distinct cytogenetic features. HER2-A = HER2 gene amplification (R:HER2/CEP17 $\geqslant 2$ in $\geqslant 10 \%$ of the cells); HER2-all-A = HER2 gene amplification in all the sample ( $\geqslant 90 \%$ of cells); HER2-CNG = HER2 gene copy number gain (presence of $\geqslant 4$ copies of the HER2 gene in $\geqslant 40 \%$ of the cells); HER2-FISH + =HER2-A and HER2-CNG; HER2-FISH + * $=$ HER2-FISH + excluding HER2-all-A (i.e., HER2-CNG and HER2-minor-A); HER2-FISH - = absence of CNG and absence of HER2 amplification; HER2-minor-A = HER2 gene amplification in a minor population (10-60\% of cells); HER2-non-A=absence of HER2 gene amplification; $\mathrm{mCRC}=$ metastatic colorectal cancer; wt = wild type.

\begin{tabular}{|c|c|c|c|c|c|c|}
\hline & \multicolumn{3}{|c|}{ PFS } & \multicolumn{3}{|c|}{ os } \\
\hline & $\mathbf{N}$ & $\begin{array}{l}\text { Median PFS } \\
\text { (months) }\end{array}$ & $\begin{array}{l}\mathrm{HR}(95 \% \mathrm{Cl} ; \\
\quad P \text {-value) }\end{array}$ & $\mathbf{N}$ & $\begin{array}{l}\text { Median PFS } \\
\text { (months) }\end{array}$ & $\begin{array}{l}\mathrm{HR}(95 \% \mathrm{Cl} ; \\
\quad \text {-value) }\end{array}$ \\
\hline All patients & 162 & 6 & & 153 & 11.3 & \\
\hline $\begin{array}{l}\text { HER2-all-A vs others (HER2- } \\
\text { non A } \\
\text { and HER2-minor-A) }\end{array}$ & 6 vs 156 & 2.5 vs 6.7 & $\begin{array}{c}3.65(1.57-8.46 ; \\
P=0.0026)\end{array}$ & 6 vs 147 & 4.2 vs 13 & $\begin{array}{c}5.05(2.17-11.77 \\
\quad P=0.0002)\end{array}$ \\
\hline $\begin{array}{l}\text { HER2-FISH + vs HER2- } \\
\text { FISH - }\end{array}$ & 107 vs 55 & 7.4 vs 3.9 & $\begin{array}{c}2.00(1.42-2.83 ; \\
\quad P<0.0001)\end{array}$ & 100 vs 53 & 12.7 vs 9.7 & $\begin{array}{l}1.18(0.83-1.69 \\
P=0.3600)\end{array}$ \\
\hline $\begin{array}{l}\text { HER2-all-A vs HER2-FISH - } \\
\text { vs HER2-FISH + }\end{array}$ & $\begin{array}{c}6 \text { vs } 55 \text { vs } \\
101\end{array}$ & 2.5 vs 3.9 vs 7.6 & & $\begin{array}{c}6 \text { vs } 53 \text { vs } \\
94\end{array}$ & 4.2 vs 9.7 vs 13 & \\
\hline HER2-all-A vs HER2-FISH - & & & $\begin{array}{l}2.28(0.96-5.40 ; \\
P=0.0606)\end{array}$ & & & $\begin{array}{l}4.36(1.82-10.89 ; \\
\quad P=0.0010)\end{array}$ \\
\hline $\begin{array}{l}\text { HER2-all-A vs HER2- } \\
\text { FISH + * }\end{array}$ & & & $\begin{array}{l}4.90(2.08-11.55 ; \\
\quad P=0.0003)\end{array}$ & & & $\begin{array}{l}5.48(2.33-12.92 \\
\quad P<0.0001)\end{array}$ \\
\hline $\begin{array}{l}\text { HER2-FISH - vs HER2- } \\
\text { FISH +* }\end{array}$ & & & $\begin{array}{l}2.15(1.51-3.05 \\
\quad P<0.0001)\end{array}$ & & & $\begin{array}{c}1.26(0.87-1.81 \\
P=0.2167)\end{array}$ \\
\hline
\end{tabular}

patients, with an HR of 5.05 (95\% CI: 2.17-11.77, $P=0.0002$; Table 2). No difference in RR was observed between the two groups (33\% vs $35 \%, P=1.0000$; Table 3).

On the contrary, patients with HER2-FISH + profile had a significant better RR $(P=0.0004$, Table 3$)$ and PFS $(P<0.0001$, Figure 4) than with HER2-FISH - . The RR for HER2-FISH + patients was $45 \%$, whereas for HER2-FISH - patients it was $17 \%$ (Table 3). The median PFS was 7.4 months for HER2-FISH + patients and 3.9 months for HER2-FISH - patients, with an HR of 2.00 (95\% CI: $1.42-2.83, P<0.0001$; Table 2). No difference in OS was observed between these two groups (median OS: 12.7 months vs 9.7 months, HR: 1.18, 95\% CI: 0.83-1.69, $P=0.3600$; Table 2).

Interestingly, three different groups of patients with significant differences in RR $(P=0.0006$, Table 3$)$, PFS $(P<0.0001$, Figure 5A) and OS $(P<0.0001$, Figure 5B) were identified in relation to HER2 gene copy number status, namely HER2-all-A, HER2-FISH - and HER2-FISH + ${ }^{*}$ (Figure 5). The RRs for these three groups were 33,17 and $46 \%$, respectively $(P=0.0006$, Table 3). HER2-all-A patients had the worst outcome, HER2-FISH - were in the middle and HER2-FISH + ${ }^{*}$ showed the highest survival probability. The median PFS was 2.5 months for HER2-all-A patients, 3.9 months for HER2-FISH - and 7.6 months for HER2-FISH $+^{*}$ (Table 2). The median OS was 4.2 months for HER2-all-A patients, 9.7 months for HER2-FISH and 13 months for HER2-FISH + ${ }^{*}$ (Table 2).

EGFR FISH analysis and the correlation with HER2 gene status. Among the 39 patients analysed for EGFR gene status, 9 (23\%) demonstrated EGFR-A. The EGFR-FISH + profile was observed in 30 patients (77\%), whereas the EGFR-FISH - profile was detected in 9 patients (23\%). Two patients (5\%) had amplifications of both the HER2 and EGFR genes (one patient was HER2all-A and the other was HER2-minor-A). Although not statistically significant, the comparison of HER2 gene status and EGFR gene status showed an interesting correlation $(P=0.0648$, Table 4$)$. The vast majority of the HER2-FISH + patients (18 out of 20,90\%) had a concomitant CNG of the EGFR gene (HER2-FISH + /EGFR$\mathrm{FISH}+$ ); the other two patients (10\%) were HER2 FISH + /EGFR FISH - . Among the 19 HER2-FISH - patients, 12 were EGFR $\mathrm{FISH}+(63 \%)$ and 7 were EGFR-FISH - (37\%) (Table 4). 


\section{DISCUSSION}

In mCRC, KRAS is the only validated biomarker used clinically to identify patients who are resistant to the anti-EGFR MoAbs cetuximab and panitumumab (Blanke et al, 2011). The alteration of other elements downstream of EGFR, such as the mutation of $B R A F, N R A S$ and PIK3CA or the loss of PTEN expression, appears to mimic KRAS mutation, but the analysis of these markers is not being used at the clinical level because they have not been validated

Table 3. Statistical analyses of correlation between HER2 gene copy number status and clinical data in terms of response rate (RR)

\section{RR}

\begin{tabular}{|l|c|c|l|}
\hline All patients & Responders & Non-responders & P-value \\
$\mathbf{N}=158$ & $\mathbf{N}=56$ & $\mathbf{N}=102$ & \\
\hline
\end{tabular}

HER2-all-A vs others (HER2-non A and HER2-minor-A)

\begin{tabular}{|l|c|c|c|}
\hline 6 & $2(33 \%)$ & $4(67 \%)$ & 1 \\
152 & $54(35 \%)$ & $98(65 \%)$ & \\
\hline
\end{tabular}

HER2-FISH + vs HER2-FISH -

\begin{tabular}{|l|c|c|l|}
\hline 104 & $47(45 \%)$ & $57(55 \%)$ & \multirow{2}{*}{0.0004} \\
54 & $9(17 \%)$ & $45(83 \%)$ & \\
\hline
\end{tabular}

HER2-all-A vs HER2-FISH - vs HER2-FISH + *

\begin{tabular}{|l|r|r|l|}
\hline 6 & $2(33 \%)$ & $4(67 \%)$ & \multirow{2}{*}{0.0006} \\
54 & $9(17 \%)$ & $45(83 \%)$ & \\
\hline 8 & $45(46 \%)$ & $53(54 \%)$ & \\
\hline
\end{tabular}

Abbreviations: FISH = fluorescent in situ hybridization; HER2-all-A $=$ HER2 gene amplification in all the sample (R:HER2/CEP17 $\geqslant 2$ in $\geqslant 90 \%$ of cells); HER2-FISH $+=$ HER2 gene copy number gain (CNG: presence of $\geqslant 4$ copies of the HER2 gene in $\geqslant 40 \%$ of the cells) and HER2-A (HER2 gene amplification as R:HER2/CEP17 $\geqslant 2$ in $\geqslant 10 \%$ of cells); HER2-FISH - = absence of CNG and absence of HER2 amplification; HER2-minor-A =HER2 gene amplification in a minor population (10-60\% of cells); HER2-non-A=absence of HER2 gene amplification. Significant $P$-values are in bold. $P$-values for RR were calculated using Chi-square test. in independent studies yet (Frattini et al, 2007; Di Nicolantonio et al, 2008; Sartore-Bianchi et al, 2009; De Roock et al, 2010).

Scarce data are available regarding the deregulation of the EGFR family members HER2, HER3 and HER4, which dimerise with EGFR and thus potentially affect the efficacy of EGFR-targeted therapies. At the preclinical level, the amplification of the HER2 gene has been shown to lead to cetuximab resistance in MCRC due to the continued activation of EGFR downstream pathways when cetuximab is bound to EGFR (Bertotti et al, 2011; Yonesaka et al, 2011).

We investigated the HER2 gene status in a cohort of $170 \mathrm{KRAS}$ wt mCRC patients treated with cetuximab or panitumumab. We

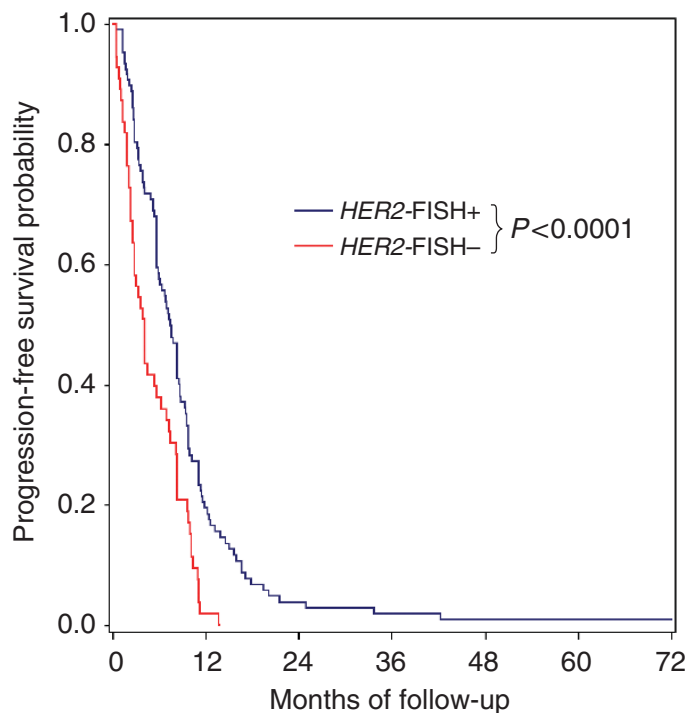

Figure 4. Kaplan-Meier curves for progression-free survival (PFS) of HER2-FISH + patients vs HER2-FISH - patients. PFS (median months): 7.4 (HER2-FISH +) vs 3.9 (HER2- FISH - ), HR: 2.00, 95\% Cl: $1.42-2.83, P<0.0001$. HER2-FISH $+=$ HER2 gene CNG (presence of $\geqslant 4$ copies of the HER2 gene in $\geqslant 40 \%$ of the cells) and HER2-A (HER2 gene amplification as R:HER2/CEP17 $\geqslant 2$ in $\geqslant 10 \%$ of cells); HER2$\mathrm{FISH}-=$ absence of CNG and absence of HER2 amplification; $\mathrm{HR}=$ hazard ratio; $\mathrm{Cl}=$ confidence interval.
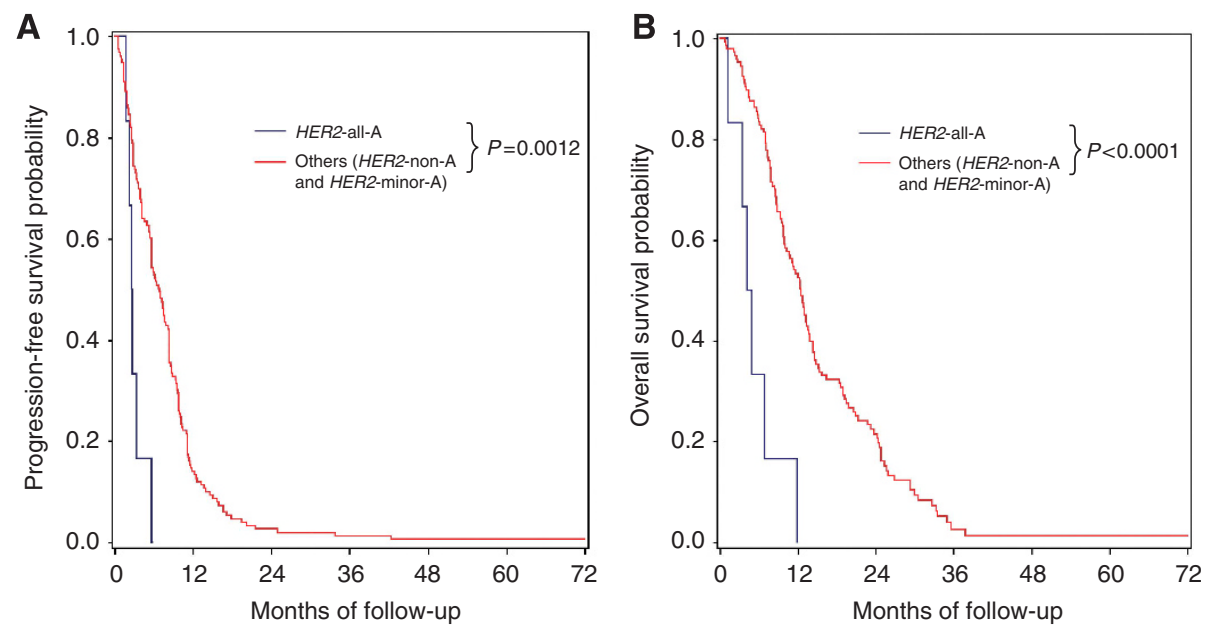

Figure 3. Kaplan-Meier curves for progression-free survival (PFS) and overall survival (OS) of HER2-all-A patients vs other patients (i.e., HER2non-A and HER2-minor-A patients). (A) PFS (median months): 2.5 (HER2-all-A) vs 6.7 (HER2 non A and HER2-minor-A), HR: 3.65, 95\% Cl: 1.578.46, $P=0.0026$. (B) OS (median months): 4.2 (HER2-all-A) vs 13 (HER2 non A and HER2-minor-A), HR: 5.05, 95\% Cl: 2.17-11.77, P=0.0002. HER2-all-A = HER2 gene amplification in all the sample ( $\geqslant 90 \%$ of cells); HER2-minor-A = HER2 gene amplification in a minor population (10-60\% of cells); HER2-non-A = absence of HER2 gene amplification; HR= hazard ratio; $\mathrm{Cl}=$ confidence interval. 

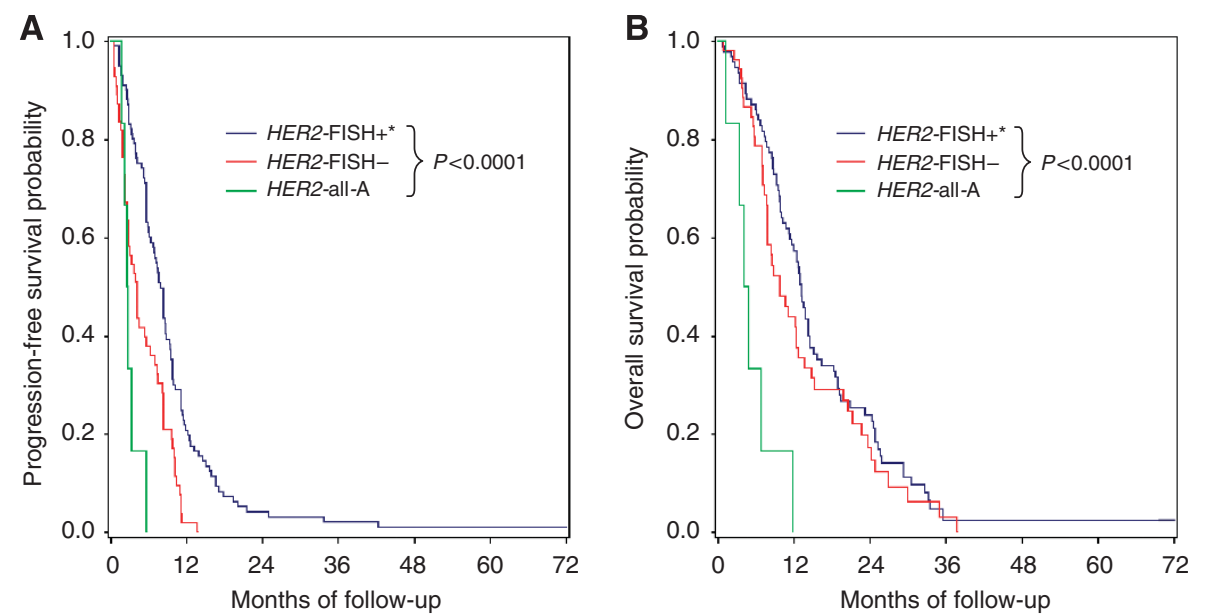

Figure 5. Kaplan-Meier curves for progression-free survival (PFS) and overall survival (OS) of HER2-all-A vs HER2-FISH + * vs HER2-FISH patients. (A) PFS (median months): 2.5 (HER2-all-A) vs 3.9 (HER2-FISH -) vs 7.6 (HER2-FISH + *). HER2-all-A vs HER2-FISH - HR: 2.28, 95\% Cl: 0.96-5.40, P=0.0606; HER2-all-A vs HER2-FISH + * HR: 4.9, 95\% Cl: 2.08-11.5, P=0.0003; HER2-FISH - vs HER2-FISH + * HR: 2.15, 95\% Cl: 1.51-3.05, P<0.0001. (B) OS (median months): 4.2 (HER2-all-A) vs 9.7 (HER2-FISH - ) vs 13 (HER2-FISH + *). HER2-all-A vs HER2-FISH - HR: 4.36, 95\% Cl: 1.82-10.89, $P=0.0010$; HER2-all-A vs HER2-FISH + * HR: 5.48, 95\% Cl: 2.33-12.92, P<0.0001; HER2-FISH - vs HER2-FISH + * HR: 1.26, $95 \% \mathrm{Cl}: 0.87-1.81, P=0.2167$. HER2-all-A = HER2 gene amplification in all the sample (R:HER2/CEP17 $\geqslant 2$ in $\geqslant 90 \%$ of cells); HER2$\mathrm{FISH}+{ }^{*}=\mathrm{HER} 2-\mathrm{FISH}+$ excluding HER2-all-A; HER2-FISH $-=$ absence of CNG and absence of HER2 amplification; HR $=$ hazard ratio.

detected HER 2 gene amplification in $20 \%$ of the patients (using $\mathrm{R}: H E R 2 / \mathrm{CEP} 17 \geqslant 2$ in $\geqslant 10 \%$ of tumour cells as criteria, according to Cappuzzo et al, 2005). This frequency is higher if compared with previously published studies that demonstrated HER2 gene amplification in $2-5 \%$ of mCRC cases (Al-Kuraya et al, 2007; Personeni et al, 2008; Bertotti et al, 2011; Yonesaka et al, 2011). The reasons for this difference may be related to the patients selection criteria (i.e., we considered only KRAS wt mCRC cases treated with MoAbs) and to discrepancy in evaluating FISH results. The interpretation of the HER2 FISH signal might be challenging in mCRC due to its peculiar morphology (the cells are packed and overlapping) and to the amplification pattern, which has greater heterogeneity (Figure 1A) than the more familiar HER2 gene amplification in breast cancer. In fact, if we consider only those cases with HER2 gene amplification in almost the entire tissue section ( $\geqslant 90 \%$ of the cells, HER2-all-A profile; Figure $1 \mathrm{~B}$ ), which are easier to recognise and are similar to the well known pattern frequently observed in breast cancer, we identified seven cases, corresponding to $4 \%$ of the entire cohort, which is consistent with the current literature.

By correlating the HER2 gene status with data of response and follow-up, we observed the existence of three distinct subgroups of patients with peculiar behaviour and different bearing to antiEGFR-MoAbs depending on HER2 gene copy number as detected by FISH. These three groups can be easily recognised if FISH evaluation is performed by describing the pattern of signals (i.e., the abnormalities revealed) and their frequency (i.e., the percentage of the cells involved; Figure 6), an approach that is recommended in the investigation of cytogenetic markers by FISH in solid tumours (Tibiletti, 2007). These classes are represented by: patients whose tumours show HER2 gene amplification in all the sample (HER2-all-A); patients with increased HER2 gene copy number due to polysomy (HER2-CNG) or to HER2 gene amplification in minor clones (HER2-minor-A); patients with no HER2 imbalance (HER2-FISH - ) (Figure 6).

Our results revealed that in KRAS wt mCRC patients, the HER2all-A status conferred resistance to cetuximab or panitumumab, thereby confirming the preliminary findings of an independent study (Bertotti et al, 2011). In addition, the HER2-all-A profile affected PFS and OS (HER2-all-A patients had the worst PFS and OS), supporting recently published data (Yonesaka et al, 2011). By

\begin{tabular}{|c|c|c|c|}
\hline Gene status by FISH & EGFR-FISH + & EGFR-FISH - & Total \\
\hline HER2-FISH + & 18 & 2 & 20 \\
\hline HER2-FISH - & 12 & 7 & 19 \\
\hline Total & 30 & 9 & 39 \\
\hline \multicolumn{4}{|c|}{$\begin{array}{l}\text { Abbreviations: EGFR =epidermal growth factor receptor; FISH = fluorescent in situ hybri } \\
\text { dization EGFR-FISH }+=E G F R-C N G \text { (i.e., EGFR gene copy number gain defined as the } \\
\text { presence of } \geqslant 4 \text { copies of the EGFR gene in } \geqslant 40 \% \text { of the cells) and EGFR-A (EGFR gene } \\
\text { amplification); EGFR-FISH }-=\text { absence of } C N G \text { and absence of EGFR amplification; HER2 } \\
\text { FISH + = HER2-CNG (i.e., HER2 gene copy number gain defined as the presence of } \geqslant 4 \\
\text { copies of the HER2 gene in } \geqslant 40 \% \text { of the cells) and HER2-A (HER2 gene amplification) } \\
\text { HER2-FISH - = absence of CNG and absence of HER2 amplification. } P=0.0648 \text {. }\end{array}$} \\
\hline
\end{tabular}

contrast, the HER2-minor-A and the HER2-CNG profiles (HER2$\mathrm{FISH}+{ }^{*}$ status) might be more likely to respond to anti-EGFR therapies. In agreement with data from non-small-cell lung cancers treated with the EGFR tyrosine kinase inhibitors gefitinib or erlotinib (Cappuzzo et al, 2007; Daniele et al, 2007; Hirsch et al, 2009), these two cytogenetic pictures represent a good prognostic marker in terms of PFS and OS. On the contrary, the HER2 normal status (FISH - ) could stand for anti-EGFR therapies inefficacy (Figure 6).

By investigating the three groups (HER2-all-A, HER2-FISH $+{ }^{*}$, HER2-FISH - ) according to their lines of treatment, we did not observe any significant correlation, although the most of HER2-allA patients were in the first or second line, whereas the most of HER2-FISH $+{ }^{*}$ were in the second or third line (data not shown). Therefore, our data seem to indicate that the changes in terms of clinical efficacy among the groups depends on patients' genetic profile rather than to the length of treatment.

From the biological point of view, the difference in response to anti-EGFR therapy between HER2-all-A tumours and HER2 $\mathrm{FISH}+{ }^{*}$ might stem from the differences in HER2 gene deregulation. In cancers where the majority of cells carry gene amplification, the HER2 oncogene is likely an essential driver of tumour growth. Therefore, HER2-all-A patients may be resistant because the majority of their cancer cells have the intrinsic ability to continuously activate downstream pathways (specifically upon 


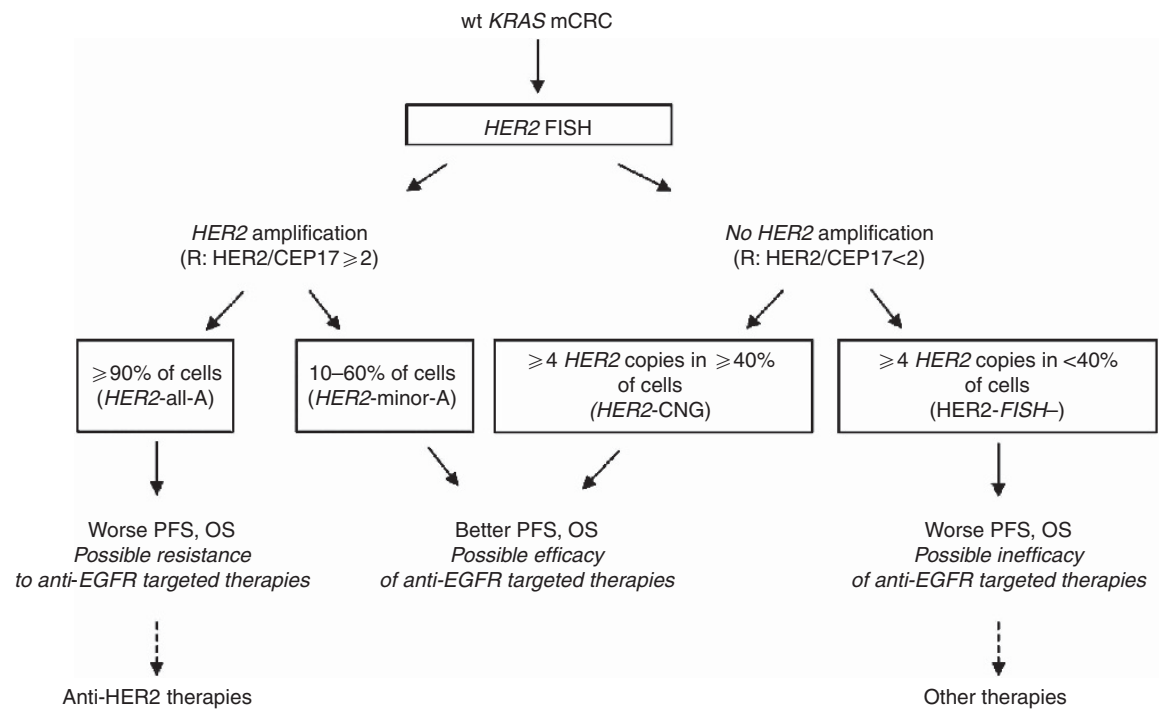

Figure 6. Practical interpretation chart to evaluate HER2 FISH profile and potential clinical implications depending on HER2 gene copy number status. $\mathrm{mCRC}=$ metastatic colorectal cancer; $\mathrm{OS}=$ overall survival; $\mathrm{PFS}=$ progression-free survival; $\mathrm{wt}=$ wild type.

HER2 stimulus), bypassing the EGFR blockade with anti-EGFR MoAbs; thus also indicating that in these patients HER2 probably represents the more important pathway with respect to EGFR, both hierarchically and biologically. By contrast, tumours with HER2 amplification in a minority of the cells or with HER2 CNG related to chromosome 7 polysomy have a different pathogenesis, and therefore their growth is probably dependent upon disruptions in other genes or other pathways. In these tumours, HER2 deregulation could result from chromosome instability, and HER2 polysomy is probably the mirror of a general polyploid karyotype, as demonstrated in mCRC using conventional cytogenetic techniques in the Mitelman Database of Chromosome Aberrations and Gene Fusions in Cancer (database online, http://cgap.nci.nih.gov/Chromosomes/Mitelman). In support of this hypothesis, we observed that nearly all of the patients with a HER2 gene CNG (90\%) had a concomitant gain of the EGFR gene (HER2 FISH + /EGFR FISH + ). Therefore, HER2 FISH + * patients might be more likely to respond to anti-EGFR drugs for reasons not strictly associated with the HER2 gene itself but rather related to the EGFR gene or to a complex karyotype.

On the other hand, the general finding that the oncogene deregulation can be linked to discordant disease behaviour depending on the proportion of cells that carry the alteration is not peculiar of HER2, as it has also been proposed for EGFR. Indeed, in non-small cell lung cancers treated with gefitinib or erlotinib, sensitive patients have the EGFR T790M mutation in only a few cells, whereas resistant patients exhibit EGFR T790M in the majority of the tumour cells (Ma et al, 2011; Benlloch et al, 2012).

The biological reason to explain the inefficacy of EGFR-targeted therapies in HER2-FISH - tumours could again be related both to kariotypic features (that probably in this case is less heterogeneous and near-diplod) or to a tumour growth that is EGFR/HER2independent, according to a recent paper ( $\mathrm{Li}$ et al, 2011), thus suggesting that other treatment regimens should be used for these patients (Figure 6).

In conclusion, our results, which deserve a confirmation in larger (not only retrospective) studies, revealed that the response to anti-EGFR MoAbs may be influenced by the HER2 gene copy number status (as detected by FISH) in KRAS wt mCRC patients. The presence of HER2 gene amplification throughout the tumour (HER2-all-A patients) is associated not only with resistance to cetuximab and panitumumab but may also identify patients who could benefit from specific anti-HER2 drugs (i.e., trastuzumab) or from combined EGFR/HER2 targeted agents (i.e., lapatinib)
(Figure 6). By contrast, HER2-CNG or amplification in a minority of tumour cells (HER2 FISH $+{ }^{*}$ ) may be a useful tool to assign patients to anti-EGFR-targeted therapies (Figure 6), thus representing an alternative option to evaluate EGFR gene status by FISH, which suffers from several limitations despite being proposed as a good predictive marker (Sartore-Bianchi et al, 2012).

Because of the aforementioned clinical implications, consistent and accurate HER2 gene copy number assessment appears to be relevant for establishing the correct therapeutic regimen in mCRC patients.

\section{ACKNOWLEDGEMENTS}

This work was supported by: Oncosuisse (to MF), Fondazione Ticinese contro il Cancro (to MF), Italian Association for Cancer Research (to FC) and Associazione Oncologia Traslazionale (to FC). ST is a senior clinical investigator of the Fund for Scientific Research Flanders and has received research grants from the Belgian Federation Against Cancer and from the Belgian National Cancer Plan.

\section{REFERENCES}

European Cytogeneticists Association Recommendations for FISH on histological sections of solid tumors. http://www.e-c-a.eu/.

Al-Kuraya K, Novotny H, Bavi P, Siraj AK, Uddin S, Ezzat A, Sanea NA, Al-Dayel F, Al-Mana H, Sheikh SS, Mirlacher M, Tapia C, Simon R, Sauter G, Terracciano L, Tornillo L (2007) HER2, TOP2A, CCND1, EGFR and C-MYC oncogene amplification in colorectal cancer. J Clin Pathol 60: 768-772.

Benlloch S, Taron M, Botero ML, Bertran-Alamillo J, Mayo C, Gimenez Capitan A, de Aguirre I, Queralt C, Ramirez JL, Rosell R, Klughammer B, Schlegel M, Chen D, Bordogna W, Ruey-Jiuan Lee J, Kovach B, O’Donnell P, Wu L, Lawrence HJ (2012) Retrospective EGFR mutation testing of clinical specimens from the EURTAC trial of erlotinib in non-small cell lung cancer (NSCLC) using a novel allele-specific PCR (AS-PCR) assy J Clin Oncol 30(suppl): abstr 10596.

Bertotti A, Migliardi G, Galimi F, Sassi F, Torti D, Isella C, Corà D, Di Nicolantonio F, Buscarino M, Petti C, Ribero D, Russolillo N, Muratore A, Massucco P, Pisacane A, Molinaro L, Valtorta E, Sartore-Bianchi A, Risio M, Capussotti L, Gambacorta M, Siena S, Medico E, Sapino A, Marsoni S, Comoglio PM, Bardelli A, Trusolino L (2011) A molecularly annotated platform of patient-derived xenografts ('xenopatients') identifies HER2 as 
an effective therapeutic target in cetuximab-resistant colorectal cancer. Cancer Discov 1: 508-523.

Blanke CD, Goldberg RM, Grothey A, Mooney M, Roach N, Saltz LB, Welch JJ, Wood WA, Meropol NJ. on behalf of the NCI GI Steering Committee Colon Cancer Task Force (2011) KRAS and colorectal cancer: ethical and pragmatic issues in effecting real-time change in oncology clinical trials and practice. Oncologist 16: 1061-1068.

Cappuzzo F, Finocchiaro G, Rossi E, Jänne PA, Carnaghi C, Calandri C, Bencardino K, Ligorio C, Ciardiello F, Pressiani T, Destro A, Roncalli M, Crino L, Franklin WA, Santoro A, Varella-Garcia M (2008) EGFR FISH assay predicts for response to cetuximab in chemotherapy refractory colorectal cancer patients. Ann Oncol 4: 717-423.

Cappuzzo F, Ligorio C, Toschi L, Rossi E, Trisolini R, Paioli D, Magrini E, Finocchiaro G, Bartolini S, Cancellieri A, Hirsch FR, Crino L, VarellaGarcia M (2007) EGFR and HER2 gene copy number and response to first-line chemotherapy in patients with advanced non-small cell lung cancer (NSCLC). J Thorac Oncol 2: 423-429.

Cappuzzo F, Varella-Garcia M, Shigematsu H, Domenichini I, Bartolini S, Ceresoli GL, Rossi E, Ludovini V, Gregorc V, Toschi L, Franklin WA, Crino L, Gazdar AF, Bunn Jr PA, Hirsch FR (2005) Increased HER2 gene copy number is associated with response to gefitinib therapy in epidermal growth factor receptor-positive non-small-cell lung cancer patients. J Clin Oncol 23: 5007-5018.

Chu E (2012) An update on the current and emerging targeted agents in metastatic colorectal cancer. Clin Colorectal Cancer 11: 1-13.

Daniele L, Macrì L, Schena M, Dongiovanni D, Bonello L, Armando E, Ciuffreda L, Bertetto O, Bussolati G, Sapino A (2007) Predicting gefitinib responsiveness in lung cancer by fluorescence in situ hybridization/ chromogenic in situ hybridization analysis of EGFR and HER2 in biopsy and cytology specimens. Mol Cancer Ther 6: 1223-1229.

De Roock W, Claes B, Bernasconi D, De Schutter J, Biesmans B, Fountzilas G, Kalogeras KT, Kotoula V, Papamichael D, Laurent-Puig P, Penault-Llorca F, Rougier P, Vincenzi B, Santini D, Tonini G, Cappuzzo F, Frattini M, Molinari F, Saletti P, De Dosso S, Martini M, Bardelli A, Siena S, SartoreBianchi A, Tabernero J, Macarulla T, Di Fiore F, Gangloff AO, Ciardiello F, Pfeiffer P, Qvortrup C, Hansen TP, Van Cutsem E, Piessevaux H, Lambrechts D, Delorenzi M, Tejpar S (2010) Effects of KRAS, BRAF, NRAS, and PIK3CA mutations on the efficacy of cetuximab plus chemotherapy in chemotherapy-refractory metastatic colorectal cancer: a retrospective consortium analysis. Lancet Oncol 11: 753-762.

Di Nicolantonio F, Martini M, Molinari F, Sartore-Bianchi A, Arena S, Saletti P, De Dosso S, Mazzucchelli L, Frattini M, Siena S, Bardelli A (2008) Wild-type BRAF is required for response to panitumumab or cetuximab in metastatic colorectal cancer. J Clin Oncol 26: 5705-5712.

Frattini M, Saletti P, Romagnani E, Martin V, Molinari F, Ghisletta M, Camponovo A, Etienne LL, Cavalli F, Mazzucchelli L (2007) PTEN loss of expression predicts cetuximab efficacy in metastatic colorectal cancer patients. Br J Cancer 97: 1139-1145.

García-Foncillas J, Díaz-Rubio E (2010) Progress in metastatic colorectal cancer: growing role of cetuximab to optimize clinical outcome. Clin Transl Oncol 12: 533-542.

Hirsch FR, Varella-Garcia M, Cappuzzo F (2009) Predictive value of EGFR and HER2 overexpression in advanced non-small-cell lung cancer. Oncogene 28: S32-S37.

Li YH, Wang F, Shen L, Deng YM, Shao Q, Feng F, An X, Wang FH, Wang ZQ, Xu RH, Shao JY (2011) EGFR fluorescence in situ hybridization pattern of chromosome 7 disomy predicts resistance to cetuximab in KRAS wild-type metastatic colorectal cancer patients. Clin Cancer Res 17: 382-390.

Ma C, Wei S, Song Y (2011) T790M and acquired resistance of EGFR TKI: a literature review of clinical reports. J Thorac Dis 3: 10-18.

Martin V, Camponovo A, Ghisletta M, Bongiovanni M, Mazzucchelli L (2012) Internal quality assurance program for ERBB2 (HER2) testing improve the selection of breast cancer patients for treatment with Trastuzumab. Patholog Res Int 2012: 261857.

Martin V, Mazzucchelli L, Frattini M (2009) An overview of the epidermal growth factor receptor fluorescence in situ hybridisation challenge in tumour pathology. J Clin Pathol 62: 314-324.
Mitelman Database of Chromosome Aberrations and Gene Fusions in Cancer [database online]. Available at: http://cgap.nci.nih.gov/Chromosomes/ Mitelman.

Moroni M, Veronese S, Benvenuti S, Marrapese G, Sartore-Bianchi A, Di Nicolantonio F, Gambacorta M, Siena S, Bardelli A (2005) Gene copy number for epidermal growth factor receptor (EGFR) and clinical response to antiEGFR treatment in colorectal cancer: a cohort study. Lancet Oncol 6: 279-286.

Personeni N, Fieuws S, Piessevaux H, De Hertogh G, De Schutter J, Biesmans B, De Roock W, Capoen A, Debiec-Rychter M, Van Laethem JL, Peeters M, Humblet Y, Van Cutsem E, Tejpar S (2008) Clinical usefulness of EGFR gene copy number as a predictive marker in colorectal cancer patients treated with cetuximab: a fluorescent in situ hybridization study. Clin Cancer Res 14: 5869-5876.

Sartore-Bianchi A, Fieuws S, Veronese S, Moroni M, Personeni N, Frattini M, Torri V, Cappuzzo F, Vander Borght S, Martin V, Skokan M, Santoro A, Gambacorta M, Tejpar S, Varella-Garcia M, Siena S (2012) Standardisation of EGFR FISH in colorectal cancer: results of an international interlaboratory reproducibility ring study. J Clin Pathol 65: 218-223.

Sartore-Bianchi A, Martini M, Molinari F, Veronese S, Nichelatti M, Artale S, Di Nicolantonio F, Saletti P, De Dosso S, Mazzucchelli L, Frattini M, Siena S, Bardelli A (2009) PIK3CA mutations in colorectal cancer are associated with clinical resistance to EGFR-targeted monoclonal antibodies. Cancer Res 69: 1851-1857.

Sartore-Bianchi A, Moroni M, Veronese S, Carnaghi C, Bajetta E, Luppi G, Sobrero A, Barone C, Cascinu S, Colucci G, Cortesi E, Nichelatti M, Gambacorta M, Siena S (2007) Epidermal growth factor receptor gene copy number and clinical outcome of metastatic colorectal cancer treated with panitumumab. J Clin Oncol 25: 3238-3245.

Sauter G, Lee J, Bartlett JM, Slamon DJ, Press MF (2009) Guidelines for human epidermal growth factor receptor 2 testing: biologic and methodologic considerations. J Clin Oncol 27: 1323-1333.

Scartozzi M, Bearzi I, Mandolesi A, Pierantoni C, Loupakis F, Zaniboni A, Negri F, Quadri A, Zorzi F, Galizia E, Berardi R, Biscotti T, Labianca R, Masi G, Falcone A, Cascinu S (2009) Epidermal Growth Factor Receptor (EGFR) gene copy number (GCN) correlates with clinical activity of irinotecan-cetuximab in K-RAS wild-type colorectal cancer: a fluorescence in situ (FISH) and chromogenic in situ hybridization (CISH) analysis. BMC Cancer 9: 303.

Tibiletti MG (2007) Interphase FISH as a new tool in tumor pathology. Cytogenet Genome Res 118: 229-236.

Van Cutsem E, Köhne CH, Láng I, Folprecht G, Nowacki MP, Cascinu S, Shchepotin I, Maurel J, Cunningham D, Tejpar S, Schlichting M, Zubel A, Celik I, Rougier P, Ciardiello F (2011) Cetuximab plus irinotecan, fluorouracil, and leucovorin as first-line treatment for metastatic colorectal cancer: updated analysis of overall survival according to tumor KRAS and BRAF mutation status. J Clin Oncol 29: 2011-2019.

Varella-Garcia M, Diebold J, Eberhard DA, Geenen K, Hirschmann A, Kockx M, Nagelmeier I, Rüschoff J, Schmitt M, Arbogast S, Cappuzzo F (2009) EGFR fluorescence in situ hybridisation assay: guidelines for application to non-small-cell lung cancer. J Clin Pathol 62: 970-977.

Wells A (1999) EGF receptor. Int J Biochem Cell Biol 31: 637-643.

Yonesaka K, Zejnullahu K, Okamoto I, Satoh T, Cappuzzo F, Souglakos J, Ercan D, Rogers A, Roncalli M, Takeda M, Fujisaka Y, Philips J, Shimizu T, Maenishi O, Cho Y, Sun J, Destro A, Taira K, Takeda K, Okabe T, Swanson J, Itoh H, Takada M, Lifshits E, Okuno K, Engelman JA, Shivdasani RA, Nishio K, Fukuoka M, Varella-Garcia M, Nakagawa K, Jänne PA (2011) Activation of ERBB2 Signaling Causes Resistance to the EGFR-Directed Therapeutic Antibody Cetuximab. Sci Transl Med 3: 99ra86.

This work is published under the standard license to publish agreement. After 12 months the work will become freely available and the license terms will switch to a Creative Commons AttributionNonCommercial-Share Alike 3.0 Unported License. 